\title{
THE EFFECT OF KNOWLEDGE MANAGEMENT AND THE ROLE OF HUMAN RESOURCES FOR STRATEGIC PLANNING AND ORGANIZATIONAL PERFORMANCE: A STUDY AT HOSPITALS OF NORTH SULAWESI, INDONESIA
}

\author{
Armanu*, Noermijati, Sudiro Achmad, Moningkey Grace \\ University of Brawijaya, Malang, Indonesia \\ *E-mail: monigre77@gmail.com
}

\begin{abstract}
The aim of this study is to determine, and evaluate the influence of the knowledge management and the role of human resources as a strategic partner in the strategic planning and organizational performance. The study conducted in public hospitals and the private sectors in the region of Nort Sulawesi with the respondent is the head of the hospital in upper and middle levels. At each hospital is given three respondents representing organizations and the unit of analysis is the organization. The data collected directly from respondents using research instruments. Techniques of analysis used partial least square (PLS). The result proves the knowledge management and the role of human resources as a strategic partner to improve the accuracy of strategic planning, and strategic planning can improve organizational performance. Knowledge management is also shown to increase the role of human resources as strategic partner. Knowledge management does not directly affect the performance of organization, but it proved that the strategic planning mediate the influence of knowledge management on organizational performance. This suggests that knowledge management is not a direct determinant of organizational performance, but its existence becomes an important input of the strategic planning process in an effort to improve organizational performance. The role of human resources as a strategic partner also not directly affects the performance of organization, and strategic planning proved to mediate the role of perfect pair strategic human resources relationship with organizational performance. This illustrates that the involvement of human resources executive as a strategic partner is not direct determinant of organizational performance, but the strategic role of a source of organizational capabilities to conduct strategic planning, in an effort to improve organizational performance. Based on these results, it means that strategic planning is based on the knowledge management and human resources role as a strategic partner can be a strategic capabilities, are valuable, rare, inimitable and non substitutable. These capabilities can become the core competencies of the organizations to improve or enhance the performance, which is a source of competitive advantage of the organization in a changing business environment rapidly.
\end{abstract}

\section{KEY WORDS}

Knowledge management, human resources, strategic partner, strategic planning, organizational performance.

The development of the economy and the business world today is changing rapidly and complexly, thus triggering various problems in the company. In this change, innovative networks and global economic movements are accelerating, so companies consciously understand that competition and information-based strategic management methods in the previous century have fundamentally changed towards knowledge-based so that strategic collaboration becomes important as mindset and practice competitive strategies. The amount of competition requires organizations to be more proactive and always think of ways to adapt and cope with an ever-changing environment. Every organization or company is required to have the ability to detect trends in environmental changes and be able to make decisions quickly.

One of the health service industries, namely the Hospital, cannot avoid these changes. Changes in the environment are so diverse, bringing changes in the views of hospital 
stakeholders. and subsequently has an impact on the paradigm shift in-hospital services. in Indonesia, the Hospital will continue to grow, both in terms of quantity and capacity, not escape the changes in the environment. The level of competition is increasing with the increasing number of operating new hospitals, especially private hospitals. Even the newly built Hospital recently claimed to be an international standard hospital. The increasing tendency of the construction of this upper-class Hospital was triggered by the influx of foreign investors, the development of the upper-middle-class population, the improved level of per capita income, and the increasingly critical public in maintaining health and choosing where to seek treatment (Azhary, 2009).

In such uncertainty and rapid environmental changes, the long-term survival of an organization is highly dependent on management's response to internal and external challenges (Athiyaman, 2010). In this case hospital management requires a management system that can anticipate changes in such a dynamic environment. Hospital leaders are important to increase their capabilities in deciding the direction of developing more adaptive and innovative hospitals to be able to survive in the environment that continues to flare up.

Strategic planning allows the company to anticipate ever-changing conditions and provides a map of the journey and the intended direction and how to achieve it (Shapiro, 2009). Companies involved in strategic planning tend to be more developed during heavy competition than those who are not. Strategic planning is an important management tool that can help organizations do their jobs better. facilitate strategy development and implementation, and organizations become more sensitive to customer and market needs Strategic planning involves how to choose the best way to respond to the dynamic and sometimes hostile environment. Strategic planning (strategic planning) is vital for the organization in maintaining its survival Determination of strategic planning as one component of the system to achieve superior performance. Strategic planning includes the selection of certain priorities both long term and short term for company development.

The key success factors for implementing strategic planning are the process of formulating a systematic strategy, implementing an effective strategy, and controlling and following up on the implementation (Brenes, et al. 2008). The flow of information and communication is critical for the overall integration and effectiveness of strategic planning (Ocasio \& Joseph, 2008). According to the resource-based view, the resource-based view of the firm (RBV) can be an enabling resource for estimating and implementing strategies that can improve company efficiency and effectiveness. Company resources and capabilities are the basic principles of strategy and the determinants of company profitability. The greater the rate of change in the external environment, the search for a basic long-term strategy of internal resources and capability is needed rather than focusing on the external market.

Regarding the role of resources in creating value, there has been a paradigm shift, that intangible assets are more important than tangible resources (Allanson, 2009; Galbreath, 2008 ) in strategic decision making (Pehrsson, 2008). Intangible assets, knowledge is widely recognized as the most important organizational asset for creating value and sustainable competitive advantage (Choi et al., 2008; Yang, et al. 2009). Organizational knowledge has proven to be a key input to the process of formulating manufacturing strategies, directing the development of capabilities to create product value (Paiva et al., 2008).

Knowledge is so strategic for the organization that knowledge management has been carried out very successfully by many leading organizations. Knowledge management is a series of processes transforming data and information into useful knowledge for various organizational interests (Serrat, 2009; Barclay \& Murray; 2009). This process includes the creation, acquisition, storage, sharing, and use of knowledge. The form and ability of organizations in managing knowledge greatly affect the quality of the knowledge generated and ultimately the quality of actions or decisions from the use of that knowledge.

Some studies have proven that knowledge management has a significant effect on organizational performance (Choi et al., 2008; Yang et al., 2009), innovation performance (Liao \& Wu, 2010) and competitive advantage (Johannessen \& Olsen, 2003; Chuang, 2004; Masa \& Testa, 2009). 
Bose (2003) examines an application system for health care organizations, where this study shows that the integration of knowledge management capabilities, technical infrastructure, and decision support architecture forms a health care management system that helps clinical and administrative decision making. Huang (2009), also studies an application system model using The Analytic Hierarchy Process (AHP) Method, asserting that a knowledge-based system (KBS) can be a strategic planning tool, planning or establishing a strategy based on informed decision making.

Likewise, Abidi (2011) in the design of a system model called Strategic Healthcare Decision-Support Services (SHDS) shows a form of KM-info oriented structure, a new approach combining synergy between knowledge procurement (Data Mining-DM) and knowledge operationalization techniques ( $\mathrm{KM}$ ), which is aimed at influencing strategic decision making, planning and management of health care companies. SHDS can provide insights, recommendations, predictions, and analyzes to help managers, policymakers and health analysts make strategic decisions or predict future possibilities. Previous studies have highlighted the importance of knowledge management for innovation, performance, competitive advantage, and strategic decisions, but the study of knowledge management associated with strategic planning is less clearly revealed. Besides, the study of knowledge management in the health services industry also received less attention from previous researchers. This study tries to fill this gap by further investigating the effect of knowledge management on strategic planning. Knowledge management as an important resource is examined its influence on the strategic planning of health service organizations.

Knowledge management resources are very closely related to human resources so that strategic planning can effectively achieve organizational performance is also very much determined by the capabilities of the human resources that will compile and realize the specified strategic plans. The success of the strategic management process largely depends on the level of human resources management functions involved. Each component of the strategic planning process, namely the formulation, implementation and evaluation of strategies, will involve people-related business issues, therefore, the human resources management function needs to be involved in each of these components. Human resources executives are seen as strategic partners with other executives and are actively involved in the strategic decision-making process (Ulrich, 1997). The role of human resources as a strategic partner focuses on the activities of matching human resources practices and strategies with corporate strategies. In playing this role, human resources executives work to become strategic partners, helping to ensure the success of the company's strategy. With this role, HR executives enhance organizational capabilities in developing and implementing strategies. The strategic role of HR becomes important and can contribute significantly to strategic planning.

Although there has been a change in the understanding of the role of the executive human resource from traditional roles that have more administrative roles (people issues) to the role of strategic human resource in creating value, studies relating to the strategic role of $\mathrm{HR}$ in the whole process of strategic planning are still limited to research and study empirically. The study has examined Ulrich's concept, and the results of its research indicate that the role of human resources as a strategic partner has a significant effect on organizational performance, but this research does not appear to have linked human resource's role as a strategic partner with strategic planning. This study tries to bridge this gap by analyzing the role of human resources as a strategic partner in the organization's strategic planning in hospitals.

From the entire set of explanation above, this research question is "how do knowledge management influence and the strategic role of human resources partners in strategic planning and organizational performance"?

- Does knowledge management have a significant effect on organizational performance?

- Does the role of human resources strategic partners have a significant effect on organizational performance? 
- Does knowledge management have a significant effect on the strategic partner role of human resources?

- Does knowledge management have a significant effect on strategic planning?

- Does the role of human resources strategic partners have a significant effect on strategic planning?

- Does strategic planning have a significant effect on organizational performance?

- Does strategic planning mediate the effect of the human resources partner's strategic role on organizational performance?

- Does strategic planning mediate the effect of knowledge management on organizational performance?

\section{CONCEPTUAL FRAMEWORK AND HYPOTHESES}

Based on the phenomena, theoretical study and empirical studies mentioned above, the conceptual framework of this research is that resources in the form of knowledge management and the strategic role of human resource partners can influence strategic planning and subsequently affect organizational performance. Knowledge management and the strategic role of human resource partners can contribute directly to organizational performance. Strategic planning can mediate the relationship between knowledge management and organizational performance. Strategic planning can also mediate the relationship between the strategic role of human resource partners and organizational performance.

Based on the research conceptual framework, the research hypotheses can be formulated as follows:

Hypothesis 1: The better knowledge management, the more precise strategic planning.

Hypothesis 2: The better the role of human resources strategic partners, the more precise strategic planning.

Hypothesis 3: The more precise strategic planning, organizational performance will increase.

Hypothesis 4: The better knowledge management, so that performance of the organization will improve

Hypothesis 5: The better strategic role of human resources partners, the better the performance of the organization.

Hypothesis 6: The better knowledge management, the better the role of strategic human resources partners.

Hypothesis 7: Strategic planning will mediate the influence of knowledge management on organizational performance.

Hypothesis 8: Strategic planning will mediate the effect of the human resources partner's strategic role on organizational performance.

\section{METHODS OF RESEARCH}

This research was conducted at public and private hospitals in North Sulawesi Province. In this study no sampling was conducted, so the entire population (40 hospitals) was used as research objects. The research respondents were the top management of the hospital (top management) and middle (middle management), including: Director, deputy director and Head of Division or Division. At each hospital 3 respondents were represented representing the organization and the unit of analysis was the organization.

The variables in this study can be identified as exogenous variables namely Knowledge Management and endogenous variables including The Role of HR Strategic Partners, Strategic Planning and Organizational Performance. Each of these variables is a latent (unobserved) variable measured by several indicators. Each indicator consists of several items which are further elaborated in the question items in the research instrument as observable variables. 
Knowledge management variable referred in this study is the capability of the hospital to acquire , storing, sharing, and using knowledge relating to the opportunities and external environmental challenges facing hospitals and knowledge of internal resources.

The variable role of strategic human resource partners in this study is the strategic role of the division or department that manages human resources in hospital organizations.

The Strategic Planning Variable in this research is the process of developing a hospital strategic plan, covering 3 stages, namely: the stage of formulation, implementation and evaluation. The stages are also an indicator of measurement of strategic planning variables and can be identified as follows: Strategy formulation; Strategy implementation; and Strategy evaluation

Organizational performance is measured by four perspectives or indicators, namely: 1). Financial perspective, measured from sales growth, net income growth, asset growth, and the results obtained by owners of capital in the last three years. 2). Customer perspective, measured from customer satisfaction, namely the level of patient / customer complaints over the quality of hospital services including: tangible aspects, reliability response-veness, assurance and empathy, referring to SERVQUAL from Parasuraman et al. (1991). 3). The operational process perspective, in this study focuses on delivering services to patients efficiently, consistently, and on time, which are characteristics of service quality. In its operation, the quality of hospital services. 4). The learning and growth perspective is measured by employee satisfaction and level of employee complaints as apart of job satisfaction.

Measurement of data used a Likert scale with a rating interval from a score of 1 (strongly disagree) to a score of 5 (strongly agree). Measurement of each indicator variable consisting of items, using the average value of the item. The unit of analysis is the institution, and each hospital is represented by 3 respondents. The value of the item scores for each hospital institution is calculated by the average value, with the formula: Average score $=\Sigma$ Item score 3.

Data collected from primary and secondary sources. Secondary data was collected from several data centers such as the Central Statistics Agency, the North Sulawesi Provincial Health Office, and other relevant publications. Primary data were collected directly from respondents using research instruments and interviews. The research instrument was first conducted a tryout to test its validity and reliability. The results of validity testing prove that all indicator variables and item questions in the research instrument are valid $(r>0.30)$. The research instrument is also reliable, given the four variables have acceptable reliability (Alpha Cronbach>0.60).

The technique analysis used in this study is variance-based Structural Equation Model called Partial Least Square (PLS). Based on the conceptual framework of research that is built based on theory and previous research studies.

\section{RESULTS AND DISCUSSION}

Knowledge management has a significant positive effect on strategic planning. These results can be interpreted, the better the knowledge management, the better strategic planningis or the more appropriate. Hypothesis 1 is proven. Knowledge management has a significant positive effect on strategic planning. These results indicate that the implementation of good knowledge management makes planning can also be done well. The better knowledge management the better organizational capabilities in strategic planning. An information created through the knowledge management process, proved that it can improve an organization's ability to formulate, implement and evaluate strategies so that strategic planning could be achieved.

The role of human resources strategic partners also has a positive and significant effect on strategic planning. These results provide evidence that the better of the strategic role of the executive of human resources in the organization, the more precise strategic planning is. This means hypothesis 2 , proven. The role of strategic human resource partners has a significant positive effect on strategic planning. These results illustrate the strategic 
role of the executive of human resources in organizations contributing significantly to the process of preparing a strategic plan. The more strategic the role of human resources the better or more precise strategic planning. Positive influences occur because human resource executives are positioned as strategic partners with other executives in the organization and are actively involved in the process of formulating, implementing and evaluating strategies.

This study also has proven that strategic planning had a significant positive effect on organizational performance. This finding can be interpreted as better or more precise strategic planning, the better or more improved organizational performance. Thus, hypothesis 3 is proven. Strategic planning has a significant positive effect on organizational performance. This shows that appropriate strategic planning contributes significantly to improving organizational performance. The more appropriate strategic planning, the better the performance of the organization. By comparing the results of this study with previous studies, it is obtained important information that in a rapidly changing environment, planning can be a very important management tool that brings more adaptive and proactive organizations to sustain targeted performance achievements.

From the results of this study, it is known that knowledge management has a positive but not significant effect on organizational performance. These results indicate that knowledge management has no direct impact on making the organization's performance improved. Thus hypothesis 4 , is not proven. The study shows that knowledge management has no significant effect on organizational performance. These results indicate that in obtaining, documenting, sharing and utilizing knowledge in an organization does not directly influence the organizational performance from such financial, customer, operational processes and learning and growth performance. Knowledge is a valuable asset that helps management in making a decision. In this case, the decision can certainly be strategic, tactical or operational, so the need for knowledge is contextual according to its purpose. Meanwhile, the impact on organizational performance is not immediate, but through strategic decisions taken.

The role of human resources strategic partners also has an insignificant effect on organizational performance. This study shows that the more efficient the role of human resources does not directly influence the organizational performance. Based on this analysis, it concluded that hypothesis 5 is also not proven. The role of human resources as a Strategic Partner is proven to have no significant effect on organizational performance. These results provide evidence that human resources as a strategic partner do not significantly contribute to the performance of the organization. The participation of human resources as strategic partners and is actively involved in the strategic decision-making process is not indicate a direct determinant of organizational performance.

Knowledge Management has a significant positive effect on the role of strategic human resource partners. From the results of this study, it can be stated the better the knowledge management, strategic role of human resource partners is also getting better. Hypothesis 6 is proven. Knowledge management has a significant positive effect on the role of Strategic Partners in human resources. This connection illustrates that the more positive knowledge management, the role of human resources as a strategic partner becomes better. To be able to play the role of a strategic partner properly, human resources certainly need the right information or knowledge at the right time related to organizational opportunities, challenges, strengths, and weaknesses. With the activities of knowledge acquisition, sharing, storing, and using applications that work well in organizations, that role can be carried out as well. As revealed in this research, knowledge management contributes significantly to the role of human resources as a strategic partner.

By focussing on the study, the mediation variable can be described as follows. The influence of knowledge management on strategic planning is significant; the effect of strategic planning on organizational performance is significant; the direct influence of knowledge management on organizational performance by involving strategic planning (mediating variables) is not-significant of ; while the direct influence of knowledge management on organizational performance without involving strategic planning variables is significant. From the results of this test show, strategic planning is a complete mediation 
variable (complete mediation) in the influence of knowledge management on organizational performance. Thus hypothesis 7 , is proven. The mediation variable proved that strategic planning mediates perfectly (complete mediation) the effect of knowledge management on organizational performance. This finding means that knowledge management is not a direct determinant of organizational performance, but its existence is an important determinant of strategic planning to lead or making improvements in organizational performance. These results indicate that organizational knowledge created the knowledge management process so it will improve organizational performance through the preparation of strategic plans with the stages of formulation, implementation, and evaluation of appropriate strategies. Organizations in maintaining their survival must emphasize the implementation of knowledge management and strategic planning as an organizational strategic capability in competing. Organizations must fully understand knowledge about external and internal conditions and carefully utilize that knowledge in formulating, implementing and evaluating strategic decisions to achieve higher organizational performance targets. The results of this study indicate that knowledge management and strategic planning are functions related to forming valuable organizational capabilities and having positive implications on organizational performance.

The mediation variables on the relationship of the strategic role of human resource partners with organizational performance can be explained as follows. The role of strategic human resource partners has a significant effect on strategic planning; the effect of strategic planning on organizational performance is significant; the direct effect of the strategic role of human resource partners on organizational performance by involving strategic planning variables is not-significant; and the direct influence of the strategic role of human resource partners on organizational performance without involving strategic planning variables is significant. Thus, from this study, it can be concluded that strategic planning is a complete mediation variable in the strategic relationship of human resource partners with organizational performance. These indicate the more strategic role of the human resource, the better the performance of the organization or increase through good or appropriate strategic planning. Thus hypothesis 8 , that strategic planning mediates the effect of the role of strategic human resource partners on organizational performance, is proven. The study showed that strategic planning perfectly mediates the relationship of the role of human resources as a strategic partner with organizational performance. These results provide evidence that in organizations, where human resources are acting as strategic partners, they can improve organizational capabilities in formulating, implementing and controlling strategies, and will further improve organizational performance in four aspects, financial, customer, operational processes and learning growth. The role of human resources as a strategic partner does not directly improve organizational performance. Thus, the capabilities of human resources are contributed well in the whole process of preparing a strategic plan and through strategic planning, the organizational performance can be improved.

\section{CONCLUSION}

The application of good knowledge management can improve the accuracy of strategic planning. This study indicates that the implementation of knowledge acquisition, sharing, storing and knowledge applications is proven to be able to improve an organization's ability to identify opportunities, challenges, strengths, and weaknesses, so that the formulation, implementation, and evaluation of strategies can be carried out appropriately. The role of strategic human resource partners can also improve the ability of organizations in strategic planning. This indicates that the division of human resources who are actively involved as the strategic partners of the organization can improve the accuracy of the formulation, implementation and evaluation or control of the strategy.

Good strategic planning implementation is proven to be able to improve organizational performance. This shows that the activities of formulation, implementation, and evaluation of the right strategy can improve organizational performance, in the financial aspects, customer satisfaction, operational processes (service quality) and learning growth (employee 
satisfaction). Knowledge management can enhance the strategic role of human resource partners. This indicates that knowledge acquisition, knowledge sharing, knowledge storing and knowledge management applications that are well implemented, can enhance the capabilities of human resources in playing the role of strategic partners, helping organiz

Based on the findings of this study, the application of knowledge management can improve organizational performance through the implementation of good strategic planning. Strategic planning perfectly mediates the influence of knowledge management on organizational performance. This indicates that the implementation of good knowledge management is not a direct determinant of organizational performance, but its existence becomes an important input throughout the strategic planning process so that efforts in improving organizational performance can be achieved.ations deal with strategic issues.

Overall it can be stated that strategic planning based on knowledge management and the strategic role of human resources partners, can be a valuable strategic organization capability, rare and cannot be imitated and substituted. Such capability can be an organization's core competency to improve or improve performance, which is a source of organizational competitive advantage in dealing with a rapidly changing business environment.

An important and interesting finding from this study is that it proves that knowledge management and the strategic role of human resource partners are important to organize intangible resources to produce good or appropriate strategic planning. Knowledge management has also proven to be an important resource for human resource to enhance their capabilities in taking part and actively participating in deciding strategic issues of the organization. Knowledge management and roles strategic human resource partners are proven not to be a direct determinant of organizational performance, but their contribution to organizational performance is through strategic planning.

In this research, it is stated that knowledge management and the role of human resources strategic partners are valuable intangible resources and as a source of organizational capability. Strategic planning based on knowledge management and the role of human resources strategic partners can be a valuable, rare and difficult organizational capability to be perfectly imitated to realize improved organizational performance which is a source of competitive advantage.

\section{SUGGESTIONS}

Organizational leaders, especially those engaged in hospital health services, it is important to pay more attention to the management of organizational knowledge, especially the need to be more careful in gaining knowledge about the external and internal environmental factors of the organization. This knowledge will determine the accuracy of strategic decisions taken in an organization's efforts to improve performance, towards increasing competitiveness.

For organizations, it is important to make knowledge management a part of routine activities. It is time for the leaders of the organization to develop policies and mechanisms that can encourage the application of knowledge management, which is the capability of the organization in acquiring, documenting, storing, sharing, and utilizing knowledge. To increase quality knowledge and in accordance with various organizational interests, the knowledge management process can also be supported by information technology tools such as the intranet or the internet, as well as the knowledge sharing culture, so that the process of creating knowledge will be faster and more effective.

\section{RESEARCH LIMITATIONS}

This study still has limitations, especially regarding the sample and research respondents. Future researchers can expand the research area, for example, to cover the territory of Indonesia, so that a more in-depth study can be done by distinguishing the type and status of hospital ownership. Research respondents can also be determined 
proportionally according to the size of the organization. In measuring organizational performance from a customer perspective, research respondents should also involve patients or customers, so they can get more objective information. Future research might also be able to apply this research framework to other business sectors.

\section{REFERENCES}

1. Abidi, Syed Sibte Raza. 2011. "Knowledge Manage- ment in Healthcare: Towards Knowledge- Driven" Decision-Support Services", Interna- tional Journal of Medical Informatics, page: 5-18.

2. Akmal. 2006. "Pengaruh Peran Manajemen Sumber Daya Manusia Terhadap Kinerja Perusahaan: Persepsikan Manajer Menengah BUMN", Usahawan, XXXV, hal. 17-23.

3. Awad, Elias M. \& Hasan M. Ghaziri. 2004. Know- ledge Management, International Edition, New Jersey: Pearson Education.

4. Azhary, M. Emil. 2009. "Potret Bisnis Rumah Sakit Indonesia", Economic Review No. 218, Desember.

5. Barclay, Rebecca O. \& Philip C. Murray. 17 Januari 2009. "What is Knowledge Management?", http://www.imamu.edu.sa/

6. Bose, Ranjit. 2003. "Knowledge Management- Enabled Health Care Management Systems: Capabilities, Infrastructure, and Decision- Support", Expert Systems with Applications, page: 59-71.

7. Bornemann, Manfred, Marion Graggober, Erich Hartlieb Bernd Humpl, Philipp Koronakis, Arthur Primus, Karl Ritsch, Herwig Rollett Martin Sammer Josef Tuppinger Reinhard Willfort \& Kurt WOls. 2 April 2003. "An Illustrated Guide to Knowledge Management", http://www.wm-forum.org.

8. Brenes, Esteban R., Mauricio Mena, German E. Molina. 2008. "Key Success Factors for Strategy Implementation in Latin America", Journal of Business research, page: 590-598.

9. Brews, Peter \& Devavrat Purohit. 2007. "Strategic Planning in Unstable Environments", Long Range Planning, page: 64-83

10. National Institute of Standards and Technology. 2008. Baldrige National Quality Program. Washington: US Department of Commerce. 